\title{
Publisher Correction: Outcompeting cancer
}

\section{Medhavi Vishwakarma (D) and Eugenia Piddini $(\mathbb{D}$}

Nature Reviews Cancer (2020) https://doi.org/10.1038/s41568-019-0231-8

Published online 13 January 2020

In the 'About this article' section of the HTML, the date stated for article acceptance (28 June 2019) was incorrect. This has been corrected to state that the article was accepted on 26 November 2019.

https://doi.org/10.1038/s41568-020-0261-2 I Published online 14 April 2020

(c) Springer Nature Limited 2020

\section{Author Correction: From melanocytes to melanomas}

\section{A. Hunter Shain and Boris C. Bastian}

Nature Reviews Cancer (2016) https://doi.org/10.1038/nrc.2016.37 Published online 29 April 2016

The second sentence in the second paragraph of the Melanocytic naevus section (p347 in the PDF) incorrectly reported data from reference 26 on superficial spreading melanomas. The sentence should have stated "Approximately $30 \%$ of non-CSD melanomas show areas representing a pre-existing common naevus ${ }^{25}$, and approximately $90 \%$ of naevus-associated melanomas are superficial spreading melanomas (a common histological presentation of non-CSD melanomas) ${ }^{26}$."

https://doi.org/10.1038/s41568-020-0269-7 I Published online 7 May 2020

๑) Springer Nature Limited 2020 